use. ${ }^{12}$ Nevertheless, there are grounds for concern about the quality of advice offered. Reliable studies tell a consistent story: although there is a wide range, traditional symptomatic treatment at pharmacies is too often inadequate; pharmacists are too often unable to identify symptoms that require referral to a doctor; and too much of the advice is given by counter assistants rather than by qualified pharmacists. ${ }^{1314}$ The findings of Goodburn and others ( $p 440$ ) are therefore broadly (and disappointingly) in line with the results of previous work. 15

Although the Royal Pharmaceutical Society is clearly concerned about the competence of community pharmacists, it is time to be rather more robust about improving standards of these aspects of pharmacy practice. ${ }^{16}{ }^{17}$ Practical therapeutics is being gradually introduced into the undergraduate pharmacy curriculum, ${ }^{17}$ but is this enough? Is it sensible to allow newly registered pharmacists to practise in the community, entirely unsupervised, without any further training? What steps will the profession take to ensure the quality of the service its members deliver? And, finally, if much of the advice given in pharmacies is to be provided by counter assistants should not they themselves be trained?

That there is an extended role for the community pharmacist is accepted by the government and many other bodies, as well as the pharmaceutical profession itself. ${ }^{3}$ The profes- sion's leaders have a considerable responsibility, however, in ensuring that the potential is fulfilled.

Professor of Clinical Pharmacology,

MICHAEL D RAWLINS

Wolfson Unit of Clinical Pharmacology

The University,

Newcastle upon Tyne NE1 7RU

1 Nuffield Foundation Committee of Inquiry. Pharmacy: the report of a committee of inquiry appointed by the Nuffield Foundation. London: Nuffield Foundation, 1986.

Edwards C. The pharmacist in primary care. Update 1987;34:134-41.

3 Pharmaceutical Services Negotiating Committee. The pharmacist's charter: extending the role of the pharmacist in the provision of health care to the community. Aylesbury: Pharmaceutical Services Negotiating Committee, 1987.

4 Royal Pharmaceutical Society. A domiciliary pharmacy service. Pharmaceutical fournal 1988 241:768.

5 Anonymous. Patient medication records [Editorial]. Pharmaceutical fournal 1989;242:327. Edwards C. Blood pressure measurement by pharmacists. $f$ R Coll Gen Pract 1981;31:674-6. Royal Pharmaceutical Society. Cholesterol testing. Pharmaceutical fournal 1988;241:786.

Morley A, Jepson MH, Edwards C, Stillman P. What do doctors think of pharmacists treating minor ailments? Pharmaceutical fournal 1983;230:387.

9 Cunningailments? Pharmaceutical fournal 1983;230:387. recommendations. Fam Pract 1988;5:122-5.

10 Cunningham-Burley S. Rediscovering the role of the pharmacist. I R Coll Gen Pract 1988;38: 99-100.

11 Morley A, Jepson MH, Edwards C, Stillman P. Should pharmacists treat minor ailments? Chemist and Druggist 1984 Jan 14:82-4.

12 Guy J, Sandler G, Brooks D. NHS data book. Lancaster: MTP Press, 1984

13 Consumers' Association. Advice across the chemist's counter. Which? 1985 Aug:351-4.

14 Mobey N, Wood A, Edwards C, Jepson MH. An assessment of the response to symptoms in community pharmacies. Pharmaceutical fournal 1986;236:807.

15 Goodburn E, Mattosinho S, Mongi P, Waterston T. The management of childhood diarrhoea by pharmacists. BMf 1991;302:440-2.

16 Anonymous. Assessment of competence: not yet [Editorial]. Pharmaceutical fournal 1990;245:475. 17 Royal Pharmaceutical Society Working Party. The feasibility of assessing competence to practise pharmacy. Pharmaceutical fournal 1990;245:496-9.

\title{
Immediate reporting of fine needle aspiration of breast lesions
}

\section{Needs an experienced aspirator and breast cytopathologist at hand}

Although widely practised elsewhere, fine needle aspiration of breast lesions with immediate reporting of cytological findings has been slow to catch on in Britain. ${ }^{1-3}$ Immediate reporting has several advantages. Unsatisfactory aspirates may be repeated immediately - thereby increasing diagnostic yield-and discussion of the diagnosis is possible with the patient on her first visit. Importantly, immediate reporting of the cytological findings does not seem to reduce the accuracy of the technique. ${ }^{1-3}$ The obvious disadvantage is that a technician and an experienced cytopathologist have to be available to stain and report the findings.

Immediate reporting of fine needle aspiration need not be restricted to palpable lesions. Stereotactic fine needle aspiration of non-palpable mammographic abnormalities is now widely practised, and results are improving. ${ }^{45}$ The advantage of having immediate reporting available is that multiple passes through such lesions - usually required to obtain a diagnosis - may be kept to a minimum if a cytopathologist is able to inspect the material aspirated on each pass. The fewer the number of passes, the less the discomfort of the procedure.

Why is "best practice" not the rule in Britain? The main reason is that in countries that provide fine needle aspiration with immediate reporting cytopathologists usually perform the aspiration, report the results, and inform the patient of the diagnosis. ${ }^{6}$ In Britain, surgeons mostly aspirate breast lumps in their outpatient clinic. Unless a technician and a cytopathologist are on hand the report is usually not available for 24-48 hours.

The technique does not have a sensitivity of $100 \%,{ }^{1367}$ and to ensure that breast cancers are not missed fine needle aspiration and cytological examination should be combined with clinical examination by an experienced clinician and, in women over 35 years, by mammography reported by an experienced radiologist. ${ }^{7}$ Mammography should be per- formed before fine needle aspiration as haematomas may produce mammographic appearances resembling those of breast carcinoma. ${ }^{8}$ Mammography is also considerably more painful when performed after fine needle aspiration. Not having the reported mammograms available when fine needle aspiration is performed means that some patients with impalpable suspicious mammographic lesions will be inappropriately reassured.

Currently, many busy surgical outpatient clinics need to defer discussion of the diagnosis and its implications for the 36-48 hours it takes to obtain the results of cytology, the delay resulting in needless anxiety for patients whose lesions are eventually found to be benign. With immediate reporting of cytological specimens patients with benign aspirates and no clinical or mammographic suspicion of malignancy may be reassured and an unnecessary biopsy avoided. ${ }^{3}$ Often patients can be discharged after their first visit. Being able to offer immediate reassurance to patients with benign disease referred from screening centres should minimise the psychiatric morbidity from screening. ${ }^{9}$

In Scandinavia fine needle aspiration of breast lesions is performed and reported by experienced staff. ${ }^{46}$ Studies from Britain have shown clearly that the technique depends on the aspirator and that results improve with experience. ${ }^{71011}$ Fine needle aspiration with immediate reporting should therefore be practised only in centres where experienced aspirators and experienced breast cytopathologists are available.

J MICHAEL DIXON

University Department of Surgery, Senior Lecturer in Surgery

Royal Infirmary of Edinburgh,

Edinburgh EH3 9YW

1 Duguid HLD, Wood RAB, Irving AD. Needle aspiration of the breast with immediate reporting of material. BMF 1979;ii:185-7. 
2 Dehn TCB, Clarke J, Dixon JM, Crucioli V, Greenall MJ, Lee ECG. Fine needle aspiration cytology, with immediate reporting in the outpatient diagnosis of breast cancer. Ann R Coll Surg Eng 1987;69:280-2.

3 Dixon JM, Clarke PJ, Crucioli V, Dehn TCB, Greenall M, Lee ECG. Reduction in biopsy rate in benign breast disease using fine needle aspiration cytology with immediate reporting. $B r f$ Surg 1987;74:1014-6.

4 Löfgren M, Andersson I, Bondeson L, Lindholm K. X ray guided fine needle aspiration for the cytologic diagnosis of non palpable breast lesions. Cancer 1988;61:1032-7.

5 Azavedo E, Svane E, Auer G. Stereotactic fine needle biopsy in 2,594 mammographically detected non palpable lesions. Lancet 1989; i: 1033-5.

6 Fransen S, Zajicek J. Aspiration biopsy in diagnosis of palpable lesions of the breast: critical review of 3,479 consecutive biopsies. Acta Radiol 1968;7:241-62.

7 Dixon JM, Lamb J, Anderson TJ, Nixon SJ, Forrest AMP. Fine needle aspiration cytology in relationship to clinical examination and mammography in the diagnosis of a solid breast mass. Brf Surg 1984;71:593-6.

Sickles EA, Klein DL, Goodson WH, Hunt TK. Mammography after fine needle aspiration of palpable breast masses. Am f Surg 1983;145:392-7.

Ellman R, Angeli N, Christians A, Moss S, Chamberlain J, Maguire P. Psychiatric morbidity associated with screening for breast cancer. Br $\mathcal{F}$ Cancer 1989;60:781-4.

10 Dixon JM, Lamb J, Anderson TJ. Fine needle aspiration cytology of solid breast lumps: the importance of the aspirator. Lancet 1983;ii:564.

11 Barrows GM, Anderson TJ, Lamb J, Dixon JM. Fine needle aspiration of breast cancer: relationship of clinical factors of cytology results in 689 primary malignancies. Cancer 986;58:1493-8.

12 Maguire P, Faulkner A. How to communicate with cancer patients: 1. Handling bad news and difficult questions. BMF 1988;297:907-9.

\title{
Thrombolytic treatment for recurrent myocardial infarction
}

\author{
Avoid repeating streptokinase or anistreplase
}

The widespread adoption of thrombolytic treatment and widening indications for its use have led to an increasing number of patients presenting to coronary care units who have previously received thrombolytic treatment. In the first year after thrombolytic treatment reinfarction occurs in about $9 \%$ of patients, ${ }^{1}$ and about $20 \%$ of patients admitted with myocardial infarction to a coronary care unit will have had a previous infarction..$^{2-4}$ Both streptokinase and anistreplase are antigenic, and after their administration antibody titres rise within a few days, peak one to two months later, and then slowly recede. High titres of antibodies might potentially be associated with major anaphylactic reactions and may result in ineffective thrombolysis. Many of the patients presenting with recurrent infarction will have received streptokinase and some will have received anistreplase. It is therefore an important issue whether these drugs should be given again.

Most patients have circulating antibodies to streptokinase as a result of a previous streptococcal infection, and for effective thrombolysis the dose of streptokinase must overcome neutralisation by antibody binding. Before Verstraete et $a l$ advocated a standard dosing regimen ${ }^{5}$ streptokinase resistance was tested and the dose modified for each patient. Streptokinase doses greater than 1.25 million units will overcome these antibodies in most patients. The currently recommended dose of 1.5 million units of streptokinase should therefore be effective in all patients except those who have recently received streptokinase or who have had a recent streptococcal infection. ${ }^{5}$

Even though some patients may have high antibody titres, the incidence of allergic reactions is low. In the second international study of infarct survival 8392 patients received streptokinase and none had anaphylactic shock. ${ }^{3}$ In 5860 patients treated in the trial by the Gruppo Italiano per lo Studio Della Streptochinasi nell'Infarto Miocardico there were seven cases of anaphylactic shock but no deaths. ${ }^{2}$

Several measurements can be made to assess the likelihood of reduced fibrinolytic activity with repeat administration of streptokinase or anistreplase. The total streptokinase resistance test measures the inhibition of fibrinolysis and reflects the contribution of $\operatorname{IgG}, \operatorname{IgM}$, and IgE streptokinase antibodies as well as plasmin inhibitors such as $\alpha_{2}$ antiplasmin. The measurement is also influenced by the amounts of fibrinogen and plasminogen present. Assays have been developed for detecting specific $\operatorname{IgG}, \operatorname{Ig} M$, and $\operatorname{IgE}$ antibodies.

Streptokinase resistance titres increase by the fifth day after administration of either streptokinase or anistreplase and remain raised in most patients for at least one year. In a small group of patients Jalihal and Morris showed that at three months all patients had neutralising titres to 1.5 million units of streptokinase. ${ }^{6}$ Massel et al showed that at one year about $70 \%$ ( $95 \%$ confidence interval $48 \%$ to $92 \%$ ) of patients who had previously received streptokinase for acute myocardial infarction had neutralising antibodies to 1.5 million units of streptokinase.

The effect of high antibody titres on lytic efficacy when these drugs are given again is uncertain. Moran et al showed a poor correlation between streptokinase specific IgG measured by radioimmunoassay and the functional streptokinase resistance titre. ${ }^{8}$ In a recent study, in which patients were given streptokinase again within a year, minor allergy was common, but analysis of cardiac enzyme activities and late coronary angiography suggested successful thrombolysis in $70 \%$ of this group. ${ }^{9}$

It remains uncertain which thrombolytic drug is best used in acute infarction. Tissue plasminogen activator is more effective than streptokinase at attaining early arterial patency as judged by a 92 minute angiogram. ${ }^{10}$ Nevertheless, there may be little difference between the drugs in terms of sustained patency, which is the likely mechanism of benefit. ${ }^{11}$ No difference has been detected between the two drugs in their effect on subsequent left ventricular function ${ }^{12}$ or on mortality. ${ }^{13}$ The results of the third international study of infarct survival comparing streptokinase, recombinant tissue plasminogen activator, and anistreplase are awaited. In the mean time streptokinase is the cheapest drug and should be used unless there are doubts about safety or efficacy.

No comparative trials are available to guide the choice of thrombolytic drug for repeat treatment. The risk of major allergic reactions seems to be low when repeat administration is delayed for more than six months, but there are uncertainties about the efficacy of repeat administration. What then can be recommended in the light of our present state of knowledge?

Although the efficacy of repeat administration of streptokinase or anistreplase has not been studied in detail, the high prevalence of raised neutralisation titres at 12 months will probably be associated with decreased thrombolytic efficacy. Treatment shown to be effective should be given and streptokinase or anistreplase should not be administered again within 12 months if non-allergic thrombolytic drugs are available.

Further information is required about antibody titres after 12 months. Meanwhile several strategies could be adopted. Jahil and Morris have recommended measuring neutralisation titres before readministering an individualised dose. ${ }^{6}$ But this may take up to an hour as several dilutions have to be made, and this approach is untenable in the light of the substantial evidence of the benefits of early thrombolytic treatment. ${ }^{2}$ Moreover, an in vitro test may not reflect the 